\title{
Klasifikasi Jeruk Nipis Terhadap Tingkat Kematangan Buah Berdasarkan Fitur Warna Menggunakan K-Nearest Neighbor
}

\author{
Cinantya Paramita ${ }^{\left.1^{*}\right)}$, Eko Hari Rachmawanto ${ }^{2}$, Christy Atika Sari ${ }^{3}$, De Rosal Ignatius Moses Setiadi ${ }^{4}$ \\ ${ }_{1,2,3,4}$ Program Studi Teknik Informatika, Fakultas Ilmu Komputer, Universitas Dian Nuswantoro, Semarang \\ 1,2,3,4 Jln. Imam Bonjol 207, Kota Semarang, 50131, Indonesia \\ email: ${ }^{1}$ cinantya.paramita@dsn.dinus.ac.id, ${ }^{2}$ eko.hari@dsn.dinus.ac.id, ${ }^{3}$ atika.sari@dsn.dinus.ac.id ${ }_{2}{ }^{4}$ moses@dsn.dinus.ac.id
}

Copyright @2019, Politeknik Harapan Bersama, Tegal

\begin{abstract}
In the process of classification of lime fruit previously done manually using the human eye is a very difficult thing to do. This is proven by being inconsistent and subjective, causing a low level of accuracy. Sometimes there are also differences of opinion from the human eye to one another. Therefore, to increase the level of accuracy and reduce the subjectivity of the human eye, this study proposes the K-Nearest Neighbor algorithm to classify the maturity level of lime based on the skin color of the lime. In this study, the $K$ values used were $9,7,5,3$ and 1 to test the search for Euclidean distance and cityblock distance distances on images with pixel sizes of 512x512, 256x256 and $128 \times 128$. In the processing stage, the extraction feature process uses mean RGB. The research that has been done proves that with Euclidean distance $k=7$ and $k=3$ has a percentage value of $92 \%$ and the cityblock distance $k=1$ and $k=3$ has a percentage value of $88 \%$. Based on the level of accuracy possessed, the color feature $k=3$ shows the best $k$ value in the classification of the maturity level of the lime fruit.
\end{abstract}

Abstrak - Pada proses klasifikasi buah jeruk nipis yang sebelumnya dilakukan manual menggunakan mata manusia merupakan hal yang sangat sulit dilakukan. Hal ini dibuktikan dengan tidak konsisten serta bersifat subyektif sehingga menyebabkan tingkat akurasi yang rendah. Terkadang ada pula perbedaan pendapat dari mata manusia satu dengan lainnya. Oleh karena itu, untuk meningkatkan tingkat akurasi serta mengurangi sifat subyektifitas mata manusia, penelitian ini mengusulkan algoritma yang dipergunakan untuk mengklasifikasikan tingkat kematangan jeruk nipis yakni $\mathrm{K}$ Nearest Neighbor berdasar kepada warna kulit yang ada pada jeruk nipis tersebut. Pada penelitian ini, nilai $K$ yang dipergunakan yakni $9,7,5,3$ serta 1 untuk menguji coba pencarian jarak Euclidean distance dan cityblock distance pada citra dengan ukuran pixel 512x512, 256x256 dan 128x128. Pada tahap prerosesing, untuk proses fitur ekstraksinya menggunakan mean RGB. Penelitian yang telah dilakukan membuktikan bahwa dengan jarak Euclidean k=7 dan $\mathrm{k}=3$ memiliki nilai prosentase $92 \%$ dan jarak cityblock distance $k=1$ dan $k=3$ memiliki nilai prosentase sebesar $88 \%$. Berdasarkan tingkat akurasi yang dimiliki, fitur warna $k=3$ menunjukkan nilai $k$ terbaik pada klasifikasi tingkat kematangan buah jeruk nipis.

*) Corresponding author: (Cinantya Paramita)

Email: cinantya.paramita@dsn.dinus.ac.id
Kata Kunci - algoritma K-Nearest Neighbor (KNN), klasifikasi, kematangan jeruk nipis, mean RGB.

\section{PENDAHULUAN}

Jeruk nipis merupakan salah satu jenis jeruk yang memiliki nilai ekonomi yang cukup tinggi dan banyak dikomsusmsi oleh masyarakat [1]. Jeruk nipis bayak digunakan oleh industri makanan dan minuman untuk memenuhi gizi masyarakat. Tingkat kematangan pada jeruk nipis dapat dilihat dari warna kulit buah jeruk nipis [2]. Kualitas produk olahan buah jeruk nipis sangat dipengaruhi oleh tingkat kematangan buah jeruk nipis. Namun, pemilihan jeruk nipis masih menggunakan penilaian mata manusia memiliki kelemahan yaitu bersifat subyektif dan tidak konsisten sehingga tingkat akurasinya rendah. Sehingga, dibutuhkan metode otomatis yang dapat meningkatkan akurasi dengan penilaian yang konsisten dalam klasifikasi tingkat kematangan jeruk nipis berasarkan fitur warna [3].

Teknik pengolahan citra digital digunakan untuk mempermudah dan mempercepat proses pengujian tingkat kematangan jeruk nipis. Inputan pada proses klasifikasi adalah karakteristik nilai fitur citra yang didapatkan dari tahap ekstraksi fitur warna menggunakan mean $R G B$ [4]. Metode klasifikasi untuk mengetahui tingkat kematangan jeruk nipis karakteristik warna adalah algoritma K-Nearest Neighbor. Trisnaningtyas, dkk [5] dalam penelitiannya menyebutkan bahwa metode K-Nearest Neighbor merupakan metode klasifikasi data yang cukup sederhana dengan akurasi yang baik yaitu bekerja berdasarkan pada jarak terdekat dari data training ke data testing dengan pemeriksaan jarak Cityblock Distance dan Euclidean Distance dan [6]. Riset klasifikasi tingkat kematangan buah jeruk sebelumnya sudah pernah dilakukan untuk identifikasi tingkat kematangan buah jeruk menggunakan teknik jaringan syaraf tiruan oleh Warman, dkk [7] menghasilkan akurasi sebesar $90 \%$ dengan menggunakan algoritma backpropagation berdasarkan warna $R G B$ dan penelitian yang menggunakan $K$-Nearest Neighbor adalah klasifikasi mutu telur berdasarkan kebersihan kerambang telur oleh Trisnaningtyas, dkk [5] yang menghasilkan akurasi tertinggi untuk $\mathrm{k}=3$ sebesar $88,89 \%$. Berdasarkan penelitian sebelumnya dan kelebihan algoritma K-Nearest Neighbor, 
makalah ini akan menggunakan algoritma tersebut untuk mengklasifikasikan dalam mengukur jeruk nipis dari tingkat kematangannya kedalam class "Mentah", "Agak Matang", "Matang", "Matang Sempurna", dan "Busuk" berdasarkan warna jeruk nipis tersebut.

\section{PENELITIAN YANG TERKAIT}

Penelitian terkait yang berhubungan dengan ekstraksi fitur dan metode K-Nearest Neighbor ditunjukkan pada Tabel I. Berdasarkan penelitian terkait dengan menggunakan algoritma K-Nearest Neighbor, makalah ini menggunakan algoritma tersebut untuk mengukur jeruk nipis dari tingkat kematangannya berdasarkan karakteristik warna $R G B$ dengan menggunakan $\mathrm{k}=1,3,5$, 7, dan 9 serta pencarian jarak Euclidean Distance dan Cityblock Distance. Data yang digunakan sebanyak 50 data latih dan 25 data uji dengan parameter 512x512 piksel, 256x256 piksel, dan 128x128 piksel.

\section{METODE PENELITIAN}

\section{A. Fitur Ekstraksi}

Fitur adalah objek yang memiliki karekteristik atau sifat. Ekstraksi fitur merupakan proses pengambilan nilai fitur atau ciri dari sebuah gambar. Ekstraksi fitur warna dilakukan dengan menghitung rata-rata setiap komponen red, green, dan blue pada citra. Hasil perhitungan mean RGB dari data latih dan uji digunakan sebagai inputan pada proses klasifikasi.

\section{B. K-Nearest Neighbor}

Metode K-Nearest Neighbor merupakan teknik pengelompokan data baru berdasarkan $k$ jarak tetangga terdekat antara informasi latih dan informasi uji [5]. Nilai $k$ yang digunakan dalam makalah ini adalah 1, 3, 5, 7, dan 9 dengan pencarian jarak antara data latih dan data uji adalah Euclidean Distance dan Cityblock Distance. Berikut adalah diagram alir klasifikasi dengan K-Nearest Neighbor sesuai Gbr 1.

Rumus Euclidean Distance pada (1) sedangkan rumus Cityblock Distance pada (2).

$$
\begin{aligned}
& d_{(x, y)}=\sqrt{\sum_{i=1}^{p}\left(x_{i}-y_{i}\right)^{2}} \\
& d_{(x, y)}=\sum_{i=0}^{p}\left|x_{i}-y_{i}\right|
\end{aligned}
$$

Dimana $d(x, y)$ : jarak data latih dan uji, $x i$ :data latih, $y i$ : data uji, $i$ : variabel data, $p:$ dimensi data.

\section{HASIL DAN PEMBAHASAN}

Citra jeruk nipis diakusisi menggunakan kamera 8 megapiksel dari Asus Zenfone A500CG pada kertas hvs berwarna putih dengan jarak $20 \mathrm{~cm}$ dari kamera. Citra akan melalui tahap preprocessing secara manual menggunakan tool paint untuk merubah ukuran citra awal menjadi ukuran 512x512 piksel, 256x256 piksel, dan 128x128 piksel. Data citra jeruk nipis berjumlah 75 data yang tebagi menjadi 50 informasi latih (data training) dan 25 informasi uji (data testing). Citra jeruk nipis terbagi atas 5 tingkat kematangan (Gbr. 2), yaitu Mentah (a), Agak Matang (b), Matang (c), Matang Sempurna (d), dan Busuk (e).

TABEL I

\begin{tabular}{|c|c|c|c|c|c|c|c|}
\hline \multirow{2}{*}{ Tahun } & \multirow{2}{*}{ Nama Peneliti } & \multicolumn{2}{|c|}{ Algoritma } & \multicolumn{4}{|c|}{ Preprosesing } \\
\hline & & KNN & LDA & GLCM & RGB & HVS & Histogram \\
\hline 2012 & Arie Qur'ania [8] & $\mathrm{v}$ & & $\mathrm{v}$ & $\mathrm{V}$ & & \\
\hline 2013 & Retno Nugroho Whidhiasih [9] & $\mathrm{V}$ & $\mathrm{v}$ & & $\mathrm{v}$ & & \\
\hline 2015 & Puspa Rizky Trisnaningtyas [5] & $\mathrm{v}$ & & $\mathrm{v}$ & & & \\
\hline 2015 & Elvia Budianita [10] & $\mathrm{v}$ & & $\mathrm{v}$ & & $\mathrm{v}$ & \\
\hline 2015 & Sigit Sugiyanto [11] & $\mathrm{v}$ & & & & $\mathrm{v}$ & \\
\hline 2015 & Febri Liantoni [12] & $\mathrm{v}$ & & & & & \\
\hline 2016 & Ion Ataka Halela [13] & $\mathrm{V}$ & & & & & $\mathrm{v}$ \\
\hline
\end{tabular}

PENELITIAN TERKAIT 


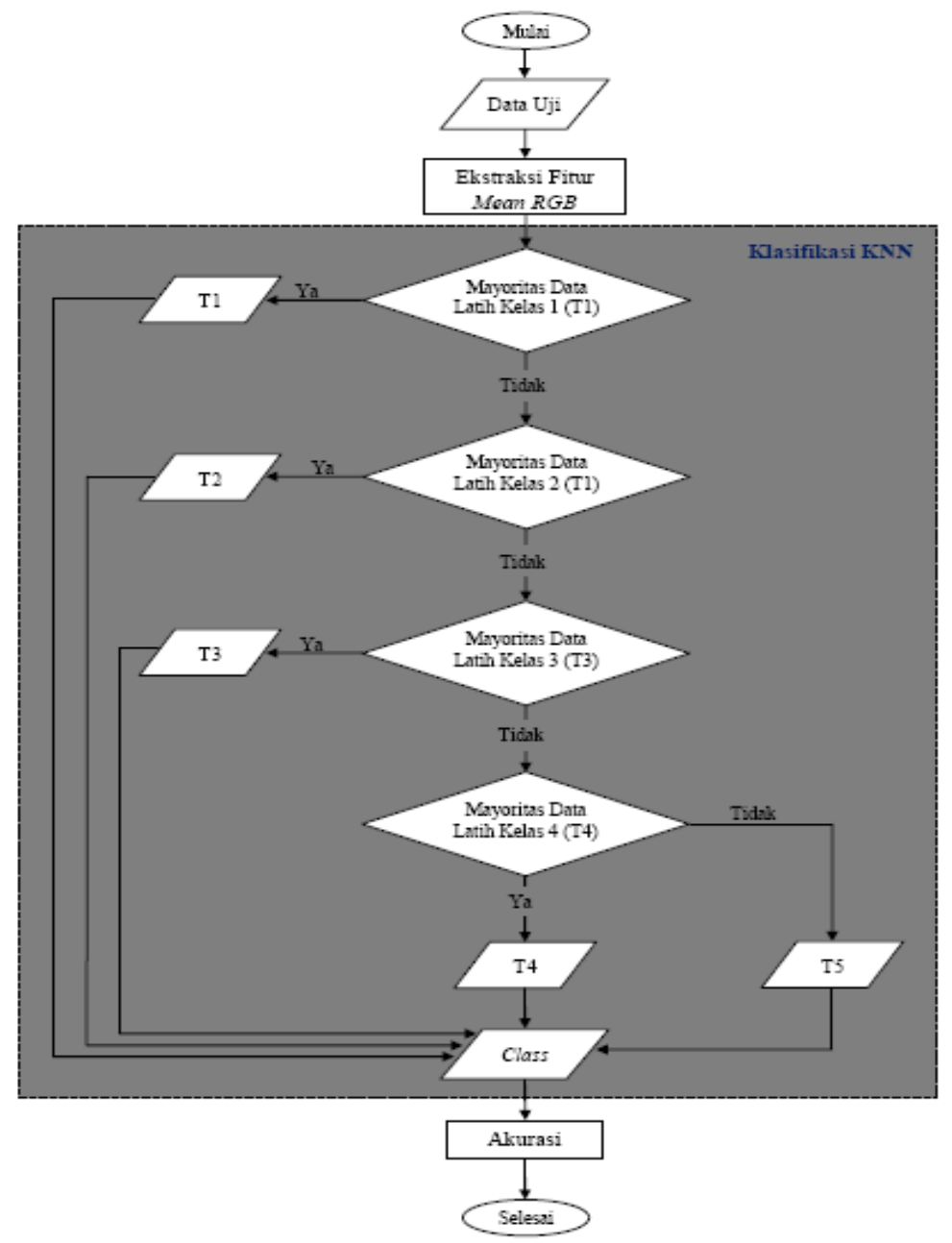

Gbr 1 . Diagram Alir K-NN

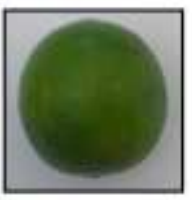

(a)

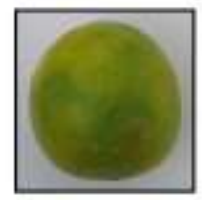

(b)

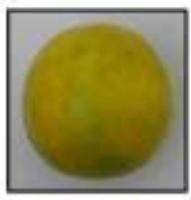

(c)

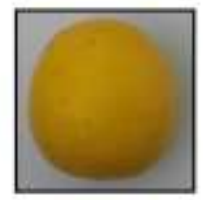

(d)

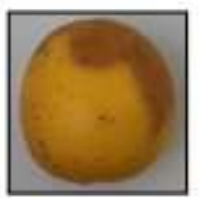

(e)

Gbr 2. Sample Citra Jeruk Nipis

Seusai Gbr. 2, pada eksperimen ini telah digunakan gambar berfomat $*$.jpg dengan jumlah 75 buah yang terdiri dari 50 data latih yang digunakan sebagai basis pengetahuan sistem dan 25 data uji untuk menguji algoritma dalam sistem. Data diambil pada kertas hvs berwarna putih dengan menggunakan kamera Asus Zenfone A500CG berukuran 8 megapiksel dengan jarak $20 \mathrm{~cm}$ dari kamera. Gambar di preprocessing dengan tool Paint untuk merubah ukuran citra menjadi 512x512 piksel, 256x256 piksel, dan 128x128 piksel. Setiap gambar buah jeruk nipis dilakukan pembagian menjadi komponen red, green, dan blue untuk proses ekstraksi menggunakan mean $R G B$ yitu menghitung rata-rata setiap komponen RGB. Hasil ekstraksi fitur data latih dan data uji digunakan sebagai inputan proses klasifikasi untuk menentukan jeruk nipis dari tingkat kematangannya berdasarkan fitur warna. Teknik klasifikasi dan ekstraksi fitur dilakukan dengan Matlab R2010a. Algoritma klasifikasi yang digunakan adalah $K$-Nearest Neighbor dengan nilai $\mathrm{k}=1,3,5$, 7, dan 9. Nilai $k$ tersebut untuk mengetahui pengaruh nilai $\mathrm{k}$ terhadap proses klasifikasi sehingga dapat mengetahui kinerja algoritma $k$-Nearest Neighbor [14][15]. Untuk menghitung pencarian jarak yakni anatara informasi latih dan informasi uji dengan Euclidean Distance dan Cityblock Distance. Metode yang diusulkan untuk mengklasifikasi jeruk nipis dari tingkat kematangannya berdasarkan fitur warna ditunjukkan pada Gbr. 3. 


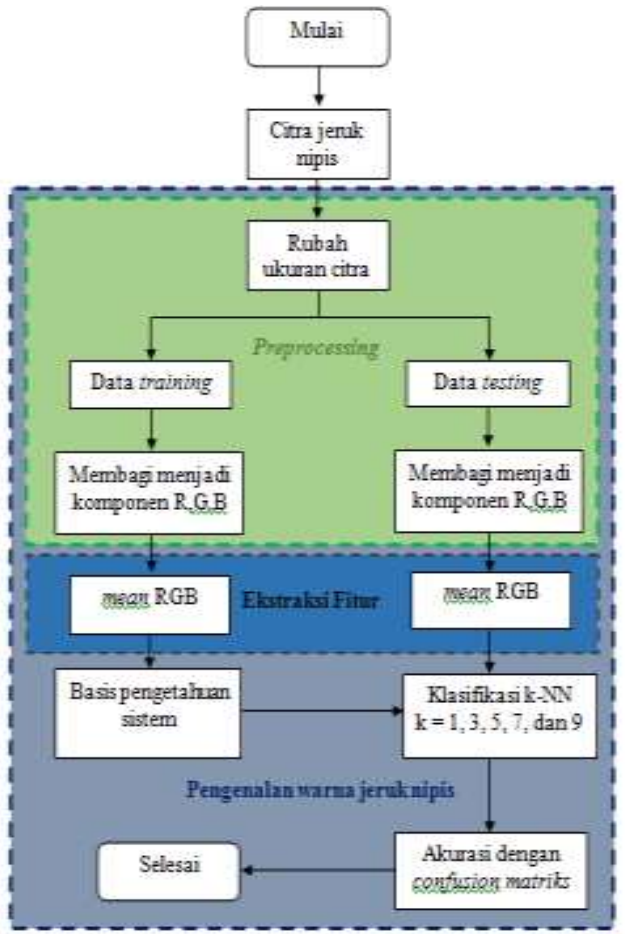

Gbr. 3 Metode Klasifikasi Jeruk Nipis Menggunakan K-NN dan Mean RGB

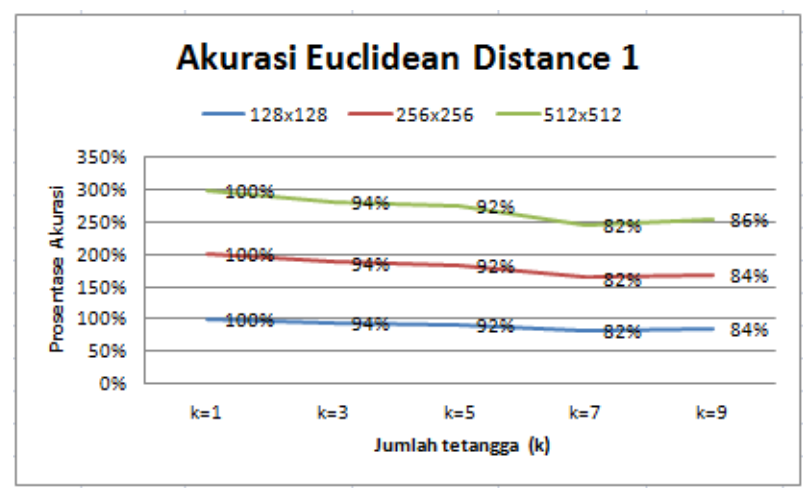

Gbr. 4 Perhitungan Akurasi menggunakan Euclidean Distance

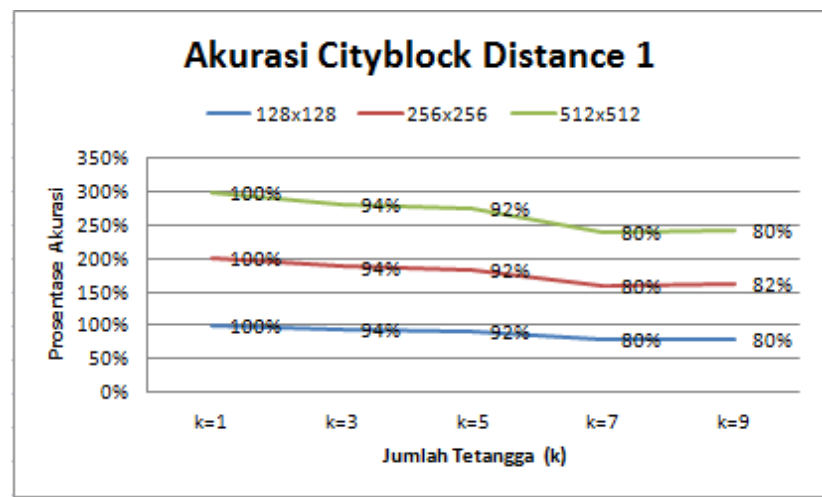

Gbr. 5 Perhitungan Akurasi menggunakan Cityblock Distance

Berdasarkan eksperimen menggunakan bagan alir pada Gbr. 3, telah dilakukan pengujian dilakukan sebanyak dua kali pengujian. Pengujian pertama dilakukan menggunakan data uji yang sama dengan data latih. Hasil percobaan pertama ditunjukan pada Gbr. 4 dan Gbr 5.
Dari Gbr. 4 dan Gbr. 5, menunjukkan bahwa akurasi tetinggi didapatkan saat menggunakan $\mathrm{k}=1$ sebesar $100 \%$, sehingga sistem layak digunakan. Percobaan kedua dilakukan menggunakan data uji yang berbeda dengan data latih. Hasil akurasi percobaan kedua ditunjukan pada Gbr. 6 dan Gbr. 7.

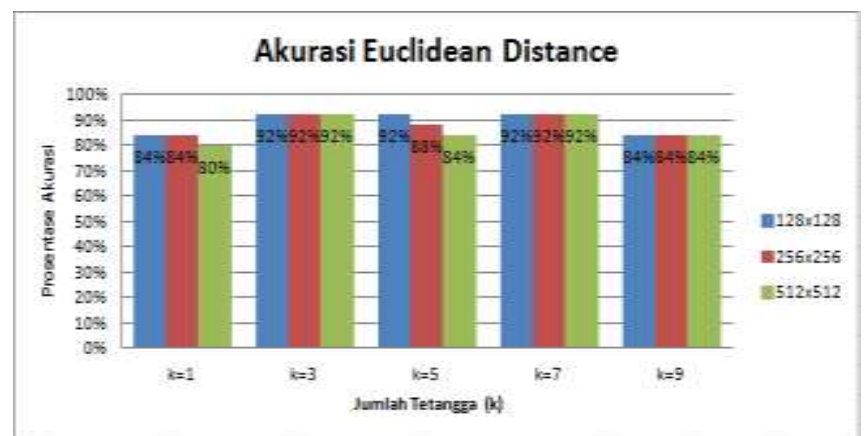

Gbr. 6 Hasil Akurasi pada Euclidean Distance

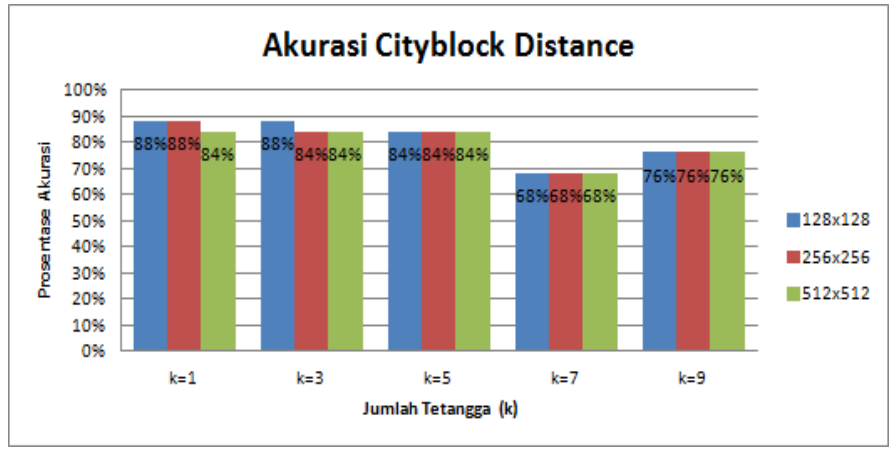

Gbr. 7 Hasil Akurasi pada Cityblock Distance

Berdasarkan Gbr. 6 dan Gbr. 7, ukuran citra tidak berpengaruh terhadap proses klasifikasi dan pencarian jarak terbaik adalah Euclidean Distance. Prosentase akurasi terbaik 
sebesar $92 \%$ didapat saat menggunakan Euclidean Distance adalah dimana nilai $\mathrm{k}=7$ dan $\mathrm{k}=3$. Sedangkan akurasi sebesar 88\% diperoleh dari metode Cityblock Distance dimana nilai $\mathrm{k}=3$ dan $\mathrm{k}=1$. Hasil klasifikasi setiap kelas untuk pencarian jarak euclidean distance menggunakan $\mathrm{k}=3$ ditunjukkan oleh Tabel II.

Tabel II menunjukkan bahwa citra jeruk nipis kelas Agak Matang dan kelas Matang Sempurna memiliki kemiripan warna dengan kelas Matang. Sedangkan untuk semua citra jeruk nipis pada kelas Mentah, kelas Matang, dan kelas Busuk telah dapat diklasifikasikan dengan benar. Perhitungan akurasi dari Tabel II.

$$
\text { Akurasi }=\frac{23}{25} \times 100 \%=92 \%
$$

Dari hasil prosentasi akurasi pada Gbr. 6 dan Gbr 7 diatas menunjukkan nilai $k$ terbaik adalah $\mathrm{k}=3$. Berikut adalah tampilan apilkasi GUI untuk mempermudah dan mempercepat proses mengklasifikasi jeruk nipis dari tingkat kematangannya berdasarkan fitur warna:

TABEL II

CONFUSION MATRIX EUCLIDEAN DISTANCE PADA K=3

\begin{tabular}{|c|c|c|c|c|c|}
\hline \multirow{3}{*}{$\begin{array}{c}\text { Kelas Asli } \\
\text { Mentah }\end{array}$} & \multicolumn{5}{|c|}{ Kelas Prediksi } \\
\hline & \multirow{2}{*}{$\begin{array}{c}\text { Mentah } \\
5\end{array}$} & \multirow{2}{*}{ Agak Matang } & \multirow{2}{*}{ Matang } & Matang Sempurna & \multirow{2}{*}{ Busuk } \\
\hline & & & & & \\
\hline Agak Matang & & 4 & 1 & & \\
\hline Matang & & & 5 & & \\
\hline Matang Sempurna & & & 1 & 4 & \\
\hline Busuk & & & & & \\
\hline
\end{tabular}

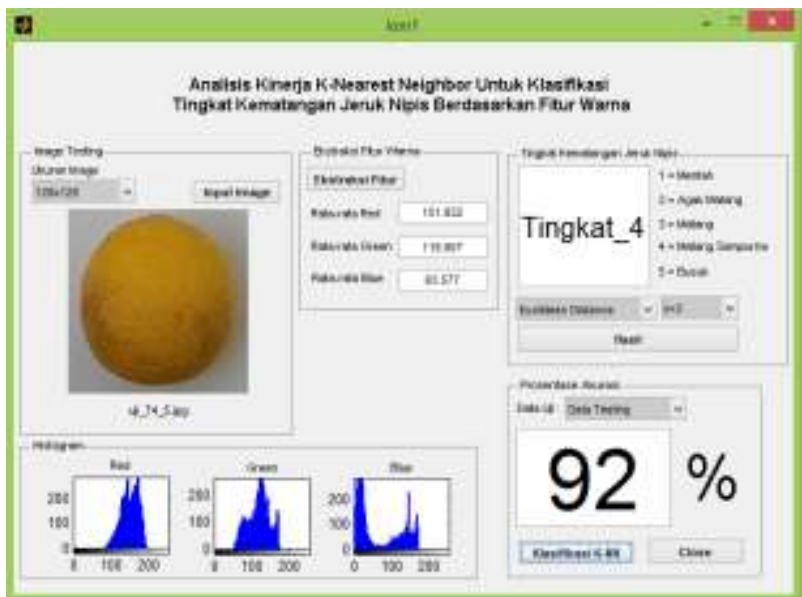

Gbr. 8 Hasil output aplikasi GUI pada Citra Jeruk Nipis Kelas 'Matang Sempurna'

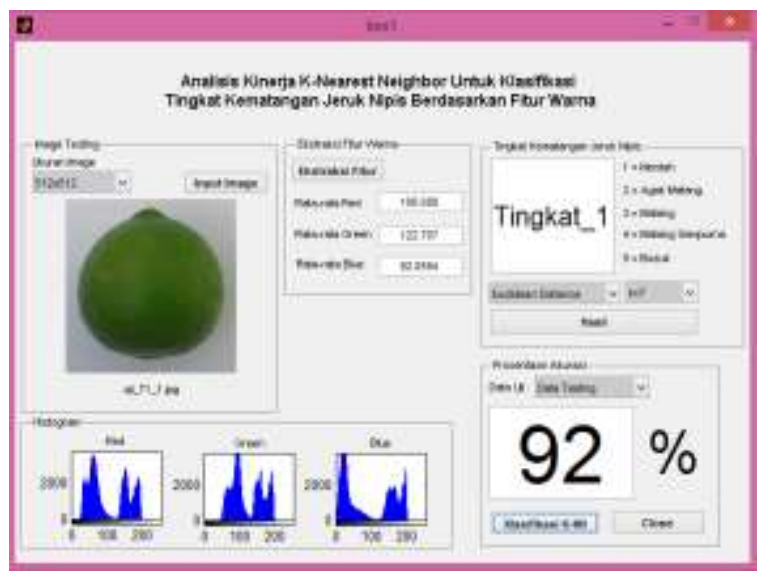

Gbr 9. Hasil output aplikasi GUI pada Citra Jeruk Nipis Kelas 'Mentah'
Pada Gbr. 8 dan Gbr. 9, kelas citra uji dengan ekstraksi mean $R G B$, jarak Euclidean distance, dan nilai $\mathrm{k}=3$ adalah matang sempurna. Sedangkan prosentase akurasi untuk data uji sebesar 92\%. Sama seperti pada Gbr. 8, pada Gbr. 9 telah disajikan inputan gambar buah jeruk nipis dari kelas Mentah dan nilai $k=7$. Hasil outputnya berupa Tingkat_1 yaitu kelas Mentah Sedangkan hasil prosentase akurasinya sama dengan $\mathrm{k}=3$ untuk data uji sebesar $92 \%$.

\section{KESIMPULAN}

Berdasarkan hasil pengujian yang sudah dilakukan pada mengklasifikasi jeruk nipis dari tingkat kematangannya berdasarkan fitur warna menggunakan metode $K$-Nearest Neighbor dapat diambil kesimpulan bahwa ekstraksi fitur mean $R G B$ dan metode $K$-Nearest Neighbor dapat diterapkan untuk mengklasifikasi jeruk nipis dari tingkat kematangannya berdasarkan fitur warna. Dari 25 data citra uji, akurasi terbaik sebesar 92\% saat menggunakan euclidean distance adalah dengan nilai $\mathrm{k}=7$ dan $\mathrm{k}=3$. Sedangkan menggunakan cityblock distance akurasi sebesar sebesar $88 \%$ dengan nilai $\mathrm{k}=3$ dan $\mathrm{k}=1$. Dari hasil prosentase akurasi menyatakan klasifikasi jeruk nipis dari tingkat kematangannya menggunakan fitur warna $\mathrm{k}$ yakni $\mathrm{k}=3$, dengan mengunakan $\mathrm{k}=7$ dan $\mathrm{k}=3$ pada pencarian jarak Euclidean distance yang menghasilkan akurasi sebesar $92 \%$, jeruk nipis dari tingkat kematangannya berdasarkan fitur warna dengan baik dan berisi mengenai kesimpulan dari penelitian yang dilakukan serta saran untuk penelitian selanjutnya.

\section{DAFTAR PUSTAKA}

[1] e. S. Prakoso, "Kajian Sifat Fisik Jeruk Manis (Citrus Sinensis) Menggunakan Pengolahan Citra Digital,” Jember, 2015.

2] Andri, Paulus, N. P. Wong, And T. Gunawan, "Segmentasi Buah Menggunakan Metode K-Means Clustering Dan Identifikasi 
Kematangannya Menggunakan Metode Perbandingan Kadar Warna,” JSM STIMIK Mikroskil, vol. 15, no. 2, pp. 91-100, 2014.

[3] S. Y. Riska, "Klasifikasi Level Kematangan Tomat Berdasarkan Perbedaan Perbaikan Citra Menggunakan Rata-Rata RGB Dan Index Pixel,” J. Ilm. Teknol. dan Informasia ASIA, vol. 9, no. 2, pp. 18-26, 2015.

[4] R. Munarto, E. Permata, and R. Salsabilla, "Klasifikasi Kualitas Biji Jagung Manis Berdasarkan Fitur Warna Menggunakan Fuzzy Logic,' in Simposium Nasional RAPI XIII, 2014, pp. 5-12.

[5] P. R. Trisnaningtyas and Maimunah, "Klasifikasi Mutu Telur Berdasarkan Kebersihan Kerabang Telur Menggunakan K-Nearest Neighbor," in Konferensi Nasional Informatika (KNIF) 2015, 2015, pp. 241-245.

[6] D. Nugraheny, "Metode Nilai Jarak Guna Kesamaan Atau Kemiripan Ciri Suatu Citra (Kasus Deteksi Awan Cumulonimbus Menggunakan Principal Component Analysis),” J. Angkasa, vol. 7, no. 2, pp. 21-30, 2015.

[7] K. Warman, L. A. Harahap, and P. achwil Munir, "Identifikas Kematangan Buah Jeruk Dengan Teknik Jaringan Syaraf Tiruan,” J. Rekayasa Pangan dan Pertan., vol. 3, no. 2, pp. 248-253, 2015.

[8] A. Qur'ania, L. Karlitasar, and S. Maryana, "Analisis Tekstur Dan Ekstraksi Fitur Warna Untuk Klasifikasi Apel Berbasis Citra," in Lokakarya Komputasi dalam Sains dan Teknologi Nuklir, 2012, pp. 296-304.
[9] R. N. Whidhiasih, N. A. Wahanani, and Supriyanto, "Klasifikasi Buah Belimbing Berdasarkan Citra Red-Green-Blue Menggunakan KNN Dan LDA,” J. Penelit. Ilmu Komputer, Syst. Embed. Log., vol. 1, no. 1, pp. 29-35, 2013.

[10] E. Budianita, Jasril, and L. Handayani, "Implementasi Pengolahan Citra dan Klasifikasi K- Nearest Neighbour Untuk Membangun Aplikasi Pembeda Daging Sapi dan Babi,” J. Sains, Teknol. dan Ind., vol. 12 , no. 2 , pp. 242-247, 2015.

[11] S. Sugiyanto and F. Wibowo, "Klasifikasi Tingkat Kematangan Buah Pepaya (Carica Papaya L) California (CALLINA-IPB 9) Dalam Ruang Warna HSV Dan Algoritma K-Nearest Neighbors," in Prosiding SENATEK, 2015, pp. 335-341.

[12] F. Liantoni, "Klasifikasi Daun Dengan Perbaikan Fitur Citra Menggunakan Metode K-Nearest Neighbor,” ULTIMATICS, vol. VII, no. 2, pp. 98-104, 2015 .

[13] I. A. Halela, "Identifikasi Jenis Buah Apel Menggunakan Algoritma K-Nearest Neighbor (KNN) dengan Ekstraksi Fitur Histogram," Semarang, 2016.

[14] N. A. Fadhlillah, "Analisis Dan Implementasi Klasifikasi K-Nearest Neighbor Telapak Kaki Manusia."

[15] D. Srianto, "Perbandingan K-Nearest Neighbor Dan Naive Bayes Untuk Klasifikasi Tanah Layak Tanam Pohon Jati," Techno.COM, vol. 15 , no. 3 , pp. 241-245, 2016. 